\title{
The penguin history of modern China: The fall and rise of a great power, 1850 to the present
}

Jonathan Fenby

Penguin Books. Londres, 2013

762 páginas

La lectura de esta voluminosa obra del reconocido periodista, editor, historiador y consultor británico, Jonathan Fenby, recompensa a quien la emprende proporcionando una visión, al mismo tiempo, panorámica y razonablemente detallada de la historia contemporánea de China.

A la luz del creciente protagonismo internacional de este gran país, la obra merece ser conocida no solo por académicos en el ámbito de los asuntos de Asia, sino por un público lector más amplio.

Como advierte el subtítulo, la narrativa se circunscribe al período que se inicia con las últimas décadas de la dinastía imperial Qing. De este modo, el libro -a diferencia, por ejemplo, de una de las historias más utilizadas en el mundo académico, como es la de John K. Fairbank- no pretende ofrecer una síntesis de la trayectoria milenaria de la historia china. En cambio, ya a partir del capítulo 6 (pág. 95), se concentra en el tumultuoso siglo XX de China, que comprende la caída del Imperio, los intentos de organización de un régimen republicano, los albores del movimiento comunista, las ofensivas japonesas, la guerra que llevaría a la fundación de la República Popular China -conflicto al mismo tiempo interno e internacional- y las fases maoísta y post-maoísta, esta última liderada por Deng Xiaoping.

Con todo, las observaciones y reflexiones que ofrece Fenby sobre China en los primeros años del presente siglo son de gran importancia. Especialmente, el epílogo constituye un notable esfuerzo de síntesis y de formulación de 
las grandes interrogantes que plantea la apuesta estratégica de Deng a la luz de la historia reciente del país: situar a la República Popular en una senda de desarrollo dinámico, diferente de los "socialismos reales", pero también de los sistemas económicos de mercado (por tanto, un "socialismo con características chinas"), manteniendo un control político férreo del país a través del poder concentrado en el Partido Comunista.

Reflexionando sobre el período actual, Fenby plantea que:

(...) La combinación de efectos del proceso lanzado por Deng Xiaoping está llevando a una etapa que podría encontrarse fácilmente en alguna época de las dinastías imperiales. Si Mao fue el fundador dinástico -fuerte y voluntarioso-, mientras que Deng fue el artífice de la consolidación, que señaló el camino para renovar el mandato, y Jiang el hábil operador que presidió un proceso de cambios importantes, Hu Jintao controló las llaves del poder sin hacer mucho, excepto reaccionar a los acontecimientos. Luego llegaron Xi Jinping y los príncipes-burócratas, conscientes de la necesidad de fortalecer el sistema, pero inhibidos por el temor de precipitar cambios destructivos. Si bien no existe una oposición organizada, el régimen enfrenta un nuevo tipo de riesgo, el cual -una vez más- tiene sus raíces en la historia de China. Desde el Primer Emperador, los gobernantes han temido perder el control sobre las grandes fuerzas en la sociedad, sea que se trate de académicos y funcionarios que plantean cuestionamientos, comandantes militares que se rebelan, o -en las últimas décadas del Imperio- de la burguesía modernizante. Hoy, quienes se ven impulsados por la atracción del mercado y el mejoramiento de las condiciones materiales, marchan cada vez más a su propio ritmo. Los grupos de interés, los individuos y centros de poder que compiten entre sí, proliferan en el marco de una estructura de poder nominalmente unitaria. Diversas empresas estatales se unen a privadas que especulan en el mercado bursátil y 
que utilizan sus posiciones para maximizar utilidades. El resultado es un Estado autoritario que tiende a carecer de autoridad, un Imperio sin un emperador (pág. 680).

Este conjunto de desafíos a la gobernabilidad comunista subyace al proyecto de concentración del poder autoritario del presidente Xi Jinping, quien -esgrimiendo el lema del «sueño chino» de estabilidad y prosperidad- ha obtenido el mandato que buscaba en el XIX Congreso del Partido Comunista que ha tenido lugar recientemente. Xi estaría restableciendo la autoridad central que se venía debilitando.

Pero en medio de estas grandes transformaciones, el legado del maoísmo sigue estando presente. Fenby es enfático en retratar el período maoísta como una serie de desastres políticos y económicos, que frustraron la temprana promesa de superación de los traumas bélicos bajo el nuevo sistema socialista. El autor describe el "Gran Salto Adelante" y la Revolución Cultural como trágicos episodios de conducción aberrante de la gran nación china. Mao fue un líder carismático, omnipotente, cruel pero también notablemente inspirado, convencido de estar en posesión de verdades superiores gracias a la ideología marxistaleninista (adaptada a China), y -dotado de una energía política sin igual- decidido a vencer cualquier obstáculo que se presentara en el camino, sin reparar en la magnitud de los sacrificios impuestos a su propio pueblo.

La enigmática personalidad de Zhou En Lai, el eterno lugarteniente comparativamente culto y racional, las complejas e inestables relaciones de Mao con su última cónyuge, la extremista Jiang Qing, y otras figuras como Lin Biao, quien pudo haber sucedido a Mao, se retratan de manera vívida, mostrando sus estrategias de poder y de supervivencia en un ambiente muchas veces conspirativo, donde las divisiones ideológicas apenas encubrían fuertes contiendas entre bambalinas.

La superación de este estilo de conducción bajo Deng y sus sucesores ha exigido, no obstante, mantener el mito político de la generación de la Larga Marcha. A diferencia de la URSS, donde pocos años después de la muerte de 
Stalin los gobernantes (a partir de Nikita Khrushchev, en 1956) condenaron las prácticas stalinistas, en China se ha escogido el camino pragmático de respetar la figura de Mao, quien a juicio general $(70 \%)$ habría tomado decisiones correctas y solo excepcionalmente $(30 \%)$ se habría equivocado. Los líderes chinos no vacilan en considerar que los dirigentes soviéticos de los años ochenta erraron completamente el camino de la reforma, al propugnar cierta apertura política junto al objetivo de la modernización económica del socialismo. La consecuencia habría sido el colapso del sistema soviético. Ese veredicto de los jerarcas chinos ayuda a explicar su enfático rechazo a cualquier relajación del control partidista en el contexto de la transformación económica. Esta conclusión subyace a la política de mantener el mito fundacional de 1949.

Sin embargo, como advirtiera la profesora Rana Mitter, historiadora de Oxford, comentando la primera edición de la obra de Fenby (Financial Times, 30 de mayo de 2008), la victoria final de las fuerzas maoístas en el largo conflicto, desde la Larga Marcha hasta la proclamación de la República Popular China, no estaba de ninguna manera asegurada. La prolongada contienda chino-japonesa; los vaivenes en las relaciones con los nacionalistas de la República de China conducidos por Chiang Kai Shek -desde la colaboración hasta el enfrentamiento sangriento, entre mediados de la década de 1920 y 1949-; los altibajos de la intervención militar de Estados Unidos, así como de las políticas de Stalin (que quería mantener a China en estado de debilidad), configuraron un cuadro geopolítico extraordinariamente complejo, que Fenby narra con maestría. De no ser por una serie de errores militares y el nunca ausente flagelo de la corrupción, el bando de Chiang podría haberse impuesto.

En su relato, Fenby (autor de una biografía del líder nacionalista) no omite episodios anecdóticos, como los esfuerzos de la mítica Madame Chiang para influir en los círculos políticos de Washington viajando a Estados Unidos y -en 1942, en China- una aventura extramarital con un enviado de F. D. Roosevelt, el político y excandidato presidencial republicano, Wendell Willkie (pág. 315). 
El propósito de estas páginas no puede ser el de ofrecer un resumen de la vasta obra de Fenby. Por citar un período, solamente la síntesis de los acontecimientos de los años ochenta, que culminaron en los trágicos sucesos de la plaza Tiananmen y que Fenby describe minuciosamente (con cierto apasionamiento), tomaría varias páginas. Resulta notable constatar la rapidez con que el régimen de Deng y sus sucesores consiguió superar el trauma nacional y la censura internacional, asociados con la represión de la protesta social y política. Desde mediados de los años noventa, para los interlocutores regionales y globales ha prevalecido cada vez más el atractivo de la modernización de China, asociado con lucrativas oportunidades de negocios. Por supuesto, se trata de hechos que en la perspectiva de la larga historia de China son todavía muy recientes. La dirigencia deduce de la narrativa de estos acontecimientos las lecciones de una política errada de relajación relativa de los controles ("liberalismo burgués"). En una cultura que se caracteriza por una fuerte conciencia histórica, estos y otros episodios cruciales se ven como hitos relevantes para la búsqueda de nuevos caminos, en el seno de los círculos de toma de decisiones del gran gigante asiático.

$\mathrm{Al}$ relatarnos de manera lúcida y documentada la gran trama de acontecimientos de casi 170 años de historia de China, Jonathan Fenby ha hecho un aporte de gran importancia a nuestro conocimiento de un país que todavía no conocemos más que de manera muy general, por no decir superficial.

Por Manfred Wilhelmy $v$. W.

Director ejecutivo CEA

Pontificia Universidad Católica de Valparaíso 